\title{
The Risk Factors and Collateral System in Coronary Artery Disease among Patients in Bandung
}

\author{
Gabriella Graziani, ${ }^{1}$ Toni M. Aprami, ${ }^{2}$ R. B. Soeherman ${ }^{3}$ \\ ${ }^{1}$ Faculty of Medicine Universitas Padjadjaran, Indonesia, ${ }^{2}$ Department of Cardiology \& Vascular \\ Medicine Faculty of Medicine Universitas Padjadjaran/Dr. Hasan Sadikin General Hospital \\ Bandung, Indonesia, ${ }^{3}$ Department of Biomedical Sciences Faculty of Medicine \\ Universitas Padjadjaran, Indonesia
}

\section{Abstract}

Background: The slow blood flow may cause atherosclerotic plaque, leading to an obstruction in the arterial circulation, and thus resulting in among others myocardial ischemia. There are many risk factors associated with the collateral system such as dyslipidemia, obesity, hypertension, diabetes mellitus, and smoking habit. This study aimed to determine the association between risk factors and collateral system in patients in Bandung.

Methods: This was an analytical cross-sectional study, using data of 186 medical records taken from Dr. Hasan Sadikin General Hospital in October 2013. The risk factors were assessed and the prevalence ratio reflected the association between the risk factors and the collateral system was analyzed.

Results: The study revealed no significant association between each risk factor and the collateral system, including obesity $(\mathrm{p}=0.690)$, smoking $(\mathrm{p}=0.175)$, dyslipidemia $(\mathrm{p}=0.747)$, and diabetes mellitus $(\mathrm{p}=0.616)$; however, only hypertension was associated $(\mathrm{p}=0.020)$. Furthermore, no significant association was found between the number of risk factor and the collateral system $(\mathrm{p}=0.233)$.

Conclusions: Of the risk factors published, only hypertension is a significant risk factor among patients in Bandung, while others including obesity, smoking, dyslipidemia and diabetes mellitus are not associated. Further study needs to be performed to explore other risk factors in coronary artery disease, and to prevent the disease among the population.

Keywords: Collateral, coronary artery disease, risk factor

\section{Introduction}

Ischemic heart disease (IHD) is the major cause of death in the world. ${ }^{1}$ According to the Ministry of Health Republic of Indonesia, cardiovascular disease, especially coronary artery disease (CAD), is the major cause of death in Indonesia and diabetes mellitus has been known as the highest co-morbidity for cardiovascular disease with 308 cases per 100.000 population. $^{2}$

In more than $90 \%$ of cases, there is a lack of blood flow that causes an atherosclerotic plaque obstruction, leading to myocardial ischemia, known as an acute coronary syndrome or an acute myocardial infarct. ${ }^{1} \mathrm{An}$ adequate collateral system of coronary arteries may prevent myocardial ischemia. ${ }^{3,4}$ However, the collateral system is sometimes affected by various risk factors such as dyslipidemia, obesity, hypertension, diabetes mellitus, and smoking habit. ${ }^{5}$

The risk factors, consisting of behavioral factors and metabolic factors, ${ }^{6}$ may affect the collateral systems in different ways. For example, a high level of lowdensity lipoprotein (LDL) is toxic for endothelial cells and smooth muscle cells; and inhibits the proliferation and migration of these cells. The oxidized LDL inhibits migration of vascular endothelial growth factor (VEGF) as an angiogenic agent. ${ }^{8}$ Furthermore, smoking inhibits growth factor secretion that plays an important role in angiogenesis. ${ }^{89}$ Other risk factor is hypertension which is characterized by a decrease in nitric oxide (NO) biosynthesis, and NO can disrupt the angiogenesis. ${ }^{10}$

The collateral system in diabetic patients is more pronounced compared to non-diabetic patients due to an impaired microvascular function. ${ }^{11}$ Interestingly, obesity is associated with impaired coronary collateral vessel 
development, thus patients with diabetes mellitus have a more affected collateral system. ${ }^{12}$ It is suggested that the more the risk factors, the more the collateral system is affected. This study aimed to determine the association between risk factors and collateral system in patients in Bandung.

\section{Methods}

This was an analytical cross-sectional study involving data from medical records from January to December 2012, taken consecutively from the medical records archive at Dr. Hasan Sadikin General Hospital in October 2013. All patients diagnosed with CAD and had an angiographic examination were included. Clinical information, such as gender, age, and various risk factors known to influence the development of collaterals, including a history of hypertension, smoking habit, obesity, dyslipidemia, and diabetes mellitus were documented. Incomplete data on risk factors and angiographic examination were excluded. This study had been approved by the Health Research Ethics Committee.

To determine the quality of the collateral systems in the angiograms, Rentrop Score was calculated by an experienced cardiologist interventionist. Patients were considered to have dyslipidemia when the total cholesterol level was $\geq 200 \mathrm{mg} / \mathrm{dL}$, triglyceride $\geq 200$ $\mathrm{mg} / \mathrm{dL}, \mathrm{LDL} \geq 130 \mathrm{mg} / \mathrm{dL}$, and High-Density Liporpotein (HDL) $<40 \mathrm{mg} / \mathrm{dL}^{7}$ Hypertension was defined as blood pressure $\geq 140 / 90$ $\mathrm{mmHg}$. Patients were considered to have diabetes mellitus when fasting blood glucose level was higher than $126 \mathrm{mg} / \mathrm{dL}$. Obesity was designated as body mass index (BMI) $\geq 30.00$ $\mathrm{kg} / \mathrm{m}^{2} \cdot{ }^{13}$

The statistical analysis was performed by Statistical Product and Service Solution (SPSS); bivariate analysis was used because this study involved one dependent variable and one independent variable. Hypothesis testing was determined by the chi-square method. The prevalence ratio (PR) was further calculated.

\section{Results}

In total, there were 223 patients admitted in the Department of Cardiology, Dr. Hasan Sadikin General Hospital, consisting of 183 men and 40 women, and only 186 had complete data as

Table 1 Baseline Characteristics

\begin{tabular}{|c|c|c|c|c|}
\hline & & \multicolumn{2}{|c|}{ Rentrop } & \multirow{2}{*}{$\begin{array}{c}\text { Total } \\
\mathbf{n}=186\end{array}$} \\
\hline \multicolumn{2}{|c|}{ Characteristics } & Good & Poor & \\
\hline \multirow{3}{*}{ Age (yr) } & Mean (SD) & 5909 (9 33) & $54.9(851)$ & \\
\hline & Median & 59 & 54 & 57 \\
\hline & Range & 44 & 42 & 53 \\
\hline \multirow[t]{2}{*}{ Sex; n (\%) } & Male & $96(82.1)$ & $58(84.1)$ & $154(82.8)$ \\
\hline & Female & $21(17.9)$ & $11(15.9)$ & $32(17.2)$ \\
\hline \multirow[t]{3}{*}{ Height (m) } & Mean (SD) & $1.63(0.07)$ & $1.62(0.07)$ & $1.63(0.07)$ \\
\hline & Median & 1.65 & 1.63 & 1.64 \\
\hline & Range & 0.38 & 0.31 & 0.38 \\
\hline \multirow[t]{3}{*}{ Weight (kg) } & Mean (SD) & $64.18(11.24)$ & $65.55(10.15)$ & $64.69(10.84)$ \\
\hline & Median & 65 & 65 & 65 \\
\hline & Range & 75 & 44 & 75 \\
\hline \multirow[t]{5}{*}{ Risk factors; n (\%) } & Obesity & $2(1.7)$ & $1(1.4)$ & $3(1.6)$ \\
\hline & Smoking & $68(58.1)$ & $47(68.1)$ & $115(61.8)$ \\
\hline & Dyslipidemia & $77(65.8)$ & $47(68.1)$ & $124(66.7)$ \\
\hline & Dm & $31(26.5)$ & $16(23.2)$ & $47(25.3)$ \\
\hline & Hypertension & $81(69.2)$ & $36(52.2)$ & 117 (62.9) \\
\hline
\end{tabular}

Note: DM=Diabetes Mellitus 
Table 2 Result of the Association between Modifiable Risk Factors and Collaterals

\begin{tabular}{|c|c|c|c|c|c|c|}
\hline & & & & & & \\
\hline Risk & tors & Poor & Good & p-value & Ratio & Interval $95 \%$ \\
\hline Obesity & Yes & 1 & 2 & & & \\
\hline & No & 68 & 115 & 0.70 & 0.90 & n.d. \\
\hline Smoking & Yes & 47 & 68 & & & \\
\hline & No & 22 & 49 & 0.18 & 1.32 & n.d. \\
\hline Dyslipidemia & Yes & 47 & 77 & & & \\
\hline & No & 22 & 40 & 0.75 & 1.07 & n.d. \\
\hline DM & Yes & 16 & 31 & 0.62 & 0.90 & n.d. \\
\hline & No & 53 & 86 & & & \\
\hline Hypertension & Yes & 36 & 81 & & & \\
\hline & No & 33 & 36 & 0.02 & 0.64 & 93 \\
\hline
\end{tabular}

Note: DM Diabetes Mellitus; n.d.=not determined

shown in Table 1. The Rentrop score was good (n117; 62.9\%) and poor (n69; 37.1\%).

The result of this study revealed that there was no association between each risk factors and the collateral system, such as obesity $(p=0.70)$, smoking $(p=0.18)$, dyslipidemia $(\mathrm{p}=0.75)$ and diabetes mellitus $(\mathrm{p}=0.62)$, however, hypertension was associated with the collateral system ( $\mathrm{p}=0.02)$, although the CI 95\% was low 0.45-0.93 (Table 2). Furthermore, no association was found between the number of risk factors involved and the collateral system $(p=0.23)$ as shown in Table 3.

\section{Discussion}

This study has shown that diabetes mellitus has no association with the collateral development, conforming study performed by Zorkun et al..$^{13}$ The collateral flow index (CFI) has been also reported to be no difference between diabetic and non-diabetic patients. ${ }^{14}$ The differentiation in cofactors that influence collaterals and the differentiation between angiogenesis and arteriogenesis may play an important role. Interestingly, our study also shows that there is no association with other coronary risk factors, including obesity, dyslipidemia, and smoking habit. The data taken in this study did not consider any treatment used by the patients. The use of antihypertensive, anti-diabetic, and lipid-lowering drugs has been considered as a positive risk factor. ${ }^{13}$

The only result with a significant finding in our study is hypertension which has an association with the collateral development. Hypertension is considered to have a protective factor from poor collateral circulation, as analyzed using the prevalence ratio. The development of collateral circulation is initiated by a steep pressure gradient between high pre-occlusive and very low post-occlusive pressure regions. Subsequently, deformation of the endothelial cells might occur through the increased pulsatile Fluid Shear Stress (FSS). The process of arteriogenesis can be drastically stimulated by increases in FSS. ${ }^{15}$

Myocardial hypoxia is the main factor in stimulating collateral circulation and to dilate stenotic coronary vessels. ${ }^{15}$ When the stenosis has occluded of $70 \%$ in the vessel

Table 3 Result of the Association between the number of Risk Factors and Collaterals

\begin{tabular}{lccccc}
\hline \multirow{2}{*}{ Rentrop } & \multicolumn{3}{c}{ Category } & \multirow{2}{*}{ Total } & p-value \\
\cline { 2 - 4 } & A & B & C & & \\
\hline Poor (score 0-1) & 17 & 48 & 4 & 69 & 0.23 \\
Good (score 2-3) & 18 & 93 & 6 & 117 & \\
Total & 35 & 141 & 10 & 186 & \\
\hline
\end{tabular}

Note: $\mathrm{A}=<2$ risk factors; $\mathrm{B}=2-3$ risk factors; $\mathrm{C}=4-5$ risk factors 
diameter, distal coronary pressure would fall and thus increase the endothelial shear stress at the other collaterals, causing a dilation of the collateral progressively through the remodeling process. ${ }^{6}$ Subsequently, the stenosis may develop into a complete occlusion and in this condition, collateral circulation may reach a maximum adaptation. ${ }^{15}$

Occlusion may cause ischemia and the development of collateral systems if the occlusions develop gradually. ${ }^{15}$ The previous study showed that the development of collateral circulation is affected by ischemic symptoms and the severity of occlusion in a long-term condition. The history of angina pectoris, pre-infarction angina, and time to cardiac catheterization are associated with a higher prevalence of collateral circulation. ${ }^{16}$ In this study, information about symptoms, length of the symptoms occurred, and the severity of the occlusions are lacking, therefore, as limitation of this study, the severity of the occlusion is not considered. Also, only one cardiologist interventionist has reviewed the angiograms, thus, no inter-observer data available.

To conclude, our study shows no association between various coronary risk factors and coronary collateral circulation, except for hypertension. Further study needs to be performed to explore other risk factors in coronary artery disease, and to prevent the disease among the population.

\section{References}

1. Kumar V, Abbas AK, Fausto N, editors. Robbins and Cotran Pathologic Basis of Disease. 7th ed. Philadelphia: Elsevier Saunders; 2005.

2. World Health Organization. Cause of death 2008: data sources and methods. Geneva: WHO; 2011

3. Ege MR, Açıgöz S, Zorlu A, Sincer I, Güray Y, Güray U, et al. Mean platelet volume: an important predictor of coronary collateral development. Platelets 2013;24(3):200-4

4. Meier P, Hemingway H, Lansky AJ, Knapp G, Pitt B, Seiler C. The impact of the coronary collateral circulation on mortality: a metaanalysis. Eur Heart J. 2012; 33(5):614-21.

5. Koerselman J, Van der Graaf Y, de Jaegere P, Grobbee DE. Coronary collaterals : an important and underexposed aspect of coronary artery disease. Circulation. 2003;107(19):2507-11.

6. Bonow RO, Mann DL, Zipes DP, Libby P, editors. Braunwald's heart disease: a textbook of cardiovascular medicine. 9th ed. Philadelphia: Elsevier Saunders; 2011.

7. Jellinger PS, Smith DA, Mehta AE, Ganda O, HandelsmanY,RodbardHW,etal.Guidelines for management of dyslipidemia and prevention of atherosclerosis: executive summary. Endocr Pract. 2012;18(2):26993.

8. Kinnaird T, Stabile E, Zbinden S, Burnett MS, Epstein SE. Cardiovascular risk factors impair native collateral development and may impair efficacy of therapeutic interventions. Cardiovasc Res. 2008;78(2):257-64.

9. Mouquet F, Cuilleret F, Susen S, Sautière K, Marboeuf P, Ennezat PV, et al. Metabolic syndrome and collateral vessel formation in patients with documented occluded coronary arteries: association with hyperglycaemia, insulin-resistance, adiponectin and plasminogen activator inhibitor-1. Eur Heart J. 2009;30(7):8409.

10. Kiefer FN, Neysari S, Humar R, Li W, Munk VC, Battegay EJ. Hypertension and angiogenesis. Curr Pharm Des. 2003:9(21):1733-44.

11. Werner GS, Richartz BM, Heinke S, Ferrari M, Figulla HR. Impaired acute collateral recruitment as a possible mechanism for increased cardiac adverse events in patients with diabetes mellitus. Eur Heart J. 2003;24(12):1134-42.

12. Yilmaz MB, Biyikoglu SF, Akin Y, Guray U, Kisacik HL, Korkmaz S. Obesity is associated with impaired coronary collateral vessel development. Int J Obes Relat Metab Disord. 2003;27(12):1541-5.

13. Zorkun C, Akkaya E, Zorlu A, Tandogan I. Determinants of Coronary collateral circulation in patients with coronary artery disease. Anadolu Kardiyol Derg. 2013;13(2):146-51.

14. Zbinden R, Zbinden S, Billinger $\mathrm{M}$, Windecker S, Meier B, Seiler C. Influence of diabetes mellitus on coronary collateral flow: an answer to an old controversy. Heart. 2005; 91(10):1289-93.

15. Schaper W. Collateral circulation past and present. Basic Res Cardiol. 2009;104(1):521.

16. Kurotobi $T$, Sato $H$, Kinjo $K$, Nakatani D, Mizuno H, Shimizu M, et al. Reduced collateral circulation to the infarctrelated artery in elderly patients with acute myocardial infarction. J Am Coll Cardiol.2004; 44(1):28-34. 